\title{
Whistle-blowing and the employment relations implications of the 'Protected Disclosures Act 2014 ' in the Republic of Ireland
}

Research Article

\author{
Lisa Halpin ${ }^{1}$ and Tony Dundon²* \\ ${ }^{1}$ National University of Ireland, Galway, Republic of Ireland \\ ${ }^{2}$ Alliance Manchester Business School, The University of Manchester, United Kingdom
}

\begin{abstract}
This article explores the introduction of the 2014 Protected Disclosures Act in the Republic of Ireland. It does so by using a justice theory lens to examine the potential for the Act to protect workers who may feel the need to blow the whistle on employer wrongdoings. Data is collected from public records and documents, along with interviews with senior representatives from 'all' the social partner agents involved in drafting or contributing to the Act. The evidence suggests that the Act may have limited utility in ensuring fairness and justice for the whistle-blower. In particular, employers appear reluctant to embrace the idea of more legal protections, while cultural stigmas attached to the idea of 'blowing the whistle' may inhibit people coming forward. The article contributes to justice theory and employment regulation, as well as whistle-blowing practices, and some recommendations are suggested to improve awareness of whistle-blowing rights for workers.
\end{abstract}

Keywords: whistle-blowing; justice theory; employment relations

(c) De Gruyter Open Sp. z 0.0 .

\section{INTRODUCTION}

In Ireland, and elsewhere, the issue of whistle-blowing is of growing concern to scholars, management practitioners, and public policy advocates (Brown et al., 2014; Hyde, 2014; Kenny, 2014; Lewis, 2015). Whistle-blowing concerns one area of employment regulation, shaped in part by the multiple roles of employers, employer associations, trade unions, and State agencies. The concept of 'regulatory space' attests to more fluid and dynamic interactions among employment actors, rather than the assumption that the government or the State is the primary or sole executive agent of regulatory impact (Hancher and Moran, 1989). Dundon et al. (2014) show how regulatory laws can be colonised by employers as a conscious attempt to weaken worker rights to participate in managerial decisionmaking processes at both transnational and national levels. More specifically, laws concerning whistle-blowing regulations require consideration of the interactions that take place not only within the foci of organisational policy but also those that occur beyond the immediate enterprise and involve the roles of actors in lobbying for legislative change (MacKenzie and Martinez-Lucio, 2014).

Lewis et al. (2015) argue that the public coverage of the government-led Francis Report of 2013 in the UK was specifically concerned with freedoms and rights for employees to speak up in health and primary care. The public review has signalled new substantial regulatory pathways to ensure justice, equality, and fairness. In Ireland, the issue of whistle-blowing has been raised as a major responsibility for regulation in key sectors, such as banking, finance, public health care, education, and policing (among others). The issue of whistle-blowing protection is now symptomatic of widespread public concern (Hyde, 2014). For example, media coverage of the Sergeant Maurice McCabe penalty points case and the Aras Attracta abuse scandal in Swinford, County Mayo, have brought regulative requirements concerning employee whistle-blowing in Ireland to the fore. The banking inquiry and the scale of potential corruption and manipulation of Ireland's financial system are issues of major public debate. Indeed, a key issue in this regard is the rights and freedoms of workers who 'blow the whistle'. Because of these debates for improved rights for those who may blow the whistle on potential employer wrongdoings, the 2014 Protected Disclosures Act was enacted in Ireland. 
There is no universal definition of whistle-blowing. Research on the topic dates back to the 1980s, with the most common definition offered by Near and Miceli (1985). They referred to whistle-blowing as 'the disclosure by organization members (former or current) of illegal, immoral or illegitimate practices under the control of their employers, to persons or organizations that may be able to effect action' (Near and Miceli, 1985: 4). This article advances two specific research aims. The first is to explore the rationale for employee whistle-blowing rights and protections as articulated by the social partners who were invited to contribute to the content of the new 2014 Act in Ireland, namely, government ministers and civil servants, trade unions, and employer associations. The second aim is broader and considers whether the new 2014 Act may improve equity and justice for workers who activate the new rights to blow the whistle. The latter objective engages in recent employment regulatory and public policy debates concerning whistle-blowing rights in Ireland. The data is only exploratory about the views of the key employment relations actors who were involved in shaping the content of the Act. Combined with some documentary content analysis, the article makes a contribution to knowledge concerning whistle-blowing employee protections and regulatory theory in Ireland.

The article is structured as follows. Next, a brief explanation of the key regulatory features of the 2014 Act is provided. A theoretical contribution is then developed that relates to fairness and justice about employment and whistle-blowing regulation in terms of procedural, distributive, and interactional justice. If regulations are to operate fairly in protecting potential whistle-blowers, best practice advice suggests that clarity of purpose and transparency of aims are important (Francis, 2013; Hyde, 2014). To this end, justice literature provides a validated lens through which to examine fairness. Following an explanation of the research methods, the findings are then presented. The article argues that the Act may have limited utility in ensuring justice for workers who feel they may have to blow the whistle concerning some employer wrongdoing. The data points to some degree of employer resistance and/or indifference to the principle of protecting employee whistle-blowers (e.g., ignoring workers' claims), along with employer negative views associated with whistle-blowing (e.g., that claims are driven by workers' self-serving interests).

\section{The 2014 Act: a brief overview}

The Act aims to improve the ease with which an organisational member (worker/manager) can make a public disclosure of a potential wrongdoing or unethical practice. The onus of proof lies on the employer to disprove the existence of a protected disclosure (Hyde, 2014). Organisations are expected to have in place a policy and failure to comply can result in a detriment to the employer in terms of the imposition of hefty fines for illicit practices. Importantly, the management (e.g., the human resources function/department) needs to fully understand the requirements of the Act as 'contracting out' responsibility is not permitted (i.e., any clause purporting to limit the operation of the Act or prevent a worker from making a protected disclosure is deemed to be void in accordance with Section 23 of the Act). Further, reliance on retrofit assumptions is not permitted. For example, a firm arguing that a long-established grievance procedure meets the requirements of the Act is unlikely to suffice: grievance procedures need to be clearly differentiated from that of whistle-blowing (Fitzgerald, 2014a).

The Act, which was implemented in July 2014, provides regulatory protection on a cross-sectoral basis for workers who feel the need to 'blow the whistle' on some aspect of their employers' practices or possible wrongdoing. It replaces the previous sectoral approach, which was deemed insufficient due to its complexity and ambiguity as to what protections applied in certain sectors or areas (Inverarity, 2014). In addition, the regulation seeks to comply with recommendations made by international bodies such as Transparency International, the United Nations, the European Parliament, and the Organisation for Economic Co-operation and Development (OECD) for 'better regulation' (Inverarity, 2014; OECD, 2012).

There are a few key requirements of the Protected Disclosures Act, 2014. Briefly, the Act extends protection to a 'worker', as opposed to exclusively protecting an 'employee' (someone engaged under a contract of service). In this regard, a wider range of individuals are covered, including agents, interns, trainees, and civil servants. Information to be disclosed must have come to the workers' attention in the course of their employment. Consequently, employers must be more conscious of the effect of their internal policies on a wider and more inclusive group of individuals working at and for an organisation (Hyde, 2014). Another significant inclusion to the 2014 Act is that the motivation of why the worker has decided to disclose information is irrelevant. The Act further specifies the requirement for a 'stepped disclosure mechanism', by which is it intended that the employer should make arrangements to first try to resolve issues internally. However, there is an exception whereby if certain conditions are fulfilled, the worker may disclose the information to someone who is not their employer (i.e., a prescribed person). 
The Act protects workers from penalisation or victimisation by their employer arising from making a protected disclosure. Workers may be awarded up to 5 years' compensation for dismissals related to them making a protected disclosure (Hyde, 2014). Further, the provision for interim relief is established in the Act, which allows workers who believe that they have been wholly or mainly dismissed for having made a protected disclosure, to apply to the Circuit Court (within 21 days of the dismissal) for interim relief. The Court may order the re-engagement, reinstatement, or the continuation of the worker's contract pending the outcome of the Unfair Dismissals case. This legal requirement means the costs and pressures on workers are eased somewhat when making a public disclosure (i.e., legal redress costs are less than when a worker makes an application for similar protection from the High Court). Overall, the 2014 Act seeks to provide the mechanisms to make a public disclosure regarding an employer's potential wrongdoing more transparent and fair relative to the employment contract while protecting the parties, especially the worker blowing the whistle.

\section{Whistle-blowing: justice theory and employment regulation}

The indeterminacy of work and employment mean that whistle-blowing is likely to be a contested terrain. Indeed, workers are typically well informed of the inner workings of an organisation and, as such, may have access to information that external regulatory bodies or the general public do not. Workers are, nonetheless, at a distinct power disadvantage relative to the authority exercised by management and their employer (Edwards, 2003). The management of people on numerous issues is fraught with issues of perceived (un)fairness, (in)justice, and (in)equality (Boxall and Purcell, 2011; O'Sullivan et al., 2015). Such complexities surrounding the management of people at work means that whistle-blowing, as a contemporary regulatory practice, is underdeveloped both conceptually and empirically.

Kenny (2012) argues that there is a deficit with regard to the theoretical development of whistle-blowing. The personal stresses involved in disclosing a corporate wrongdoing or malpractice can affect perceptions of fairness and legitimacy and have implications for employee's identity and self-esteem (Kenny, 2015). Importantly, numerous factors, both internal (e.g., managerial attitudes, role of unions, etc.) and external (e.g., employer associations, laws, regulations, etc.), relate to peoples' perceptions of the justice and legitimacy concerning whistle-blowing rights. Above all, the potential victimisation of a worker by the employer following a disclosure of information is likely to be shaped by power and authority relations over-and-above individual perceptions of whistle-blowing and, thus, connect to the core theory of the management of employment.

The term 'whistle-blower' is not mentioned anywhere in the text of the Irish 2014 Act. What is defined is a 'protected disclosure', which refers to the disclosure of relevant information (whether before or after the date of the passing of this Act) made by a worker in a specified manner (i.e., to their employer, a prescribed person, a Minister, a legal advisor, etc.). Theoretically, perceptions of fairness about organisational policy and especially how managers enact regulations into actual practice have been shown to provide important insights concerning the power dynamic embedded in managing people (Heffernan and Dundon, 2016). Justice theory can help better understand those issues and perceptions of fairness or injustice surrounding employment regulations that may prompt workers (or managers) to blow the whistle on an issue or practice. As Near et al. (1993) have noted, from the whistle-blowers' point of view, satisfaction with organisational procedure will depend on their perception of procedural fairness.

Justice theory has advanced understanding about the complexities and tensions surrounding employment regulation and management policy (Farndale et al., 2011). Colquitt (2001) shows that an employee will determine the fairness of management policy in line with what procedures are in place. Frenkel et al. (2012) report that effective HR policies foster positive perceptions of justice. Near et al. (1993) report validity in the justice theory concept as a tool to analyse the reactions of both the employer (e.g., the recipient of a public disclosure) and the employee (e.g., the whistle-blower). We now briefly assess the relevance of 'procedural (legal)', 'distribute (resource allocation)', and 'interactional (relationship)' justice dimensions for whistle-blowing regulation.

Procedural (legal) justice. Kahn-Freund (1977) suggests that the law has three separate and distinct functions (regulatory, restrictive, and auxiliary), which can affect policy and practice. Auxiliary power relates to the encouragement of certain norms and sanctions surrounding the bargaining process to regulate the behaviour of the parties towards one another. The regulation of the employment contract is crucially a key feature of government control in establishing (or removing) legal rights and obligations (Hyman, 2008). Kahn-Freund (1977) aptly explains that legal regulation is 'a countervailing force to counteract the inequality of bargaining power which is inherent in, and must be inherent in the employment relationship' (Kahn-Freund, 1977: 6). However, in Ireland, employment 
regulation is increasingly influenced by organised employer lobbying, including that of inward-investing multinational corporations, which typically favours the interests of capital over labour (Collings et al., 2008).

The regulation for whistle-blowing rights resonates with an examination of the procedural dimension of justice. In short, are new whistle-blowing rules and laws likely to be perceived as procedurally fair? Importantly, line managers and supervisors often determine procedural fairness, and workers are likely to engage in whistle-blowing if matters are not adequately handled internally (Regh et al., 2008). It is unlikely that a worker will perceive legal regulations as fair if such laws easily allow managerial retaliation or victimisation of the worker (Hyde, 2014). The new whistleblower Act in Ireland purports to ensure protection for those making a public disclosure, regardless of whether the disclosure was made internally or externally. Therefore, it is the intention of the Act to ensure procedural equality by outlawing victimisation as a result of making a disclosure (Table 1). In addition, those who make a protected disclosure should not experience any subsequent adverse consequences, including selective downsizing, ostracism, harassment by superiors, and victimisation. Potentially, a procedurally just and equitable whistle-blower policy may assist in not only achieving legal compliance (e.g., eliminating fraud and corruption) but also encouraging managerial innovation through more engaged employee voice and freedom of speech speak-up programmes (Carr and Lewis, 2010).

Table 1. Justice dimensions, people management, and public disclosure protective goals

\begin{tabular}{llll}
\hline & $\begin{array}{l}\text { Distributive (Resource } \\
\text { Allocation) Justice }\end{array}$ & $\begin{array}{l}\text { Procedural (Legal, Rule- } \\
\text { making) Justice }\end{array}$ & $\begin{array}{l}\text { Interactional } \\
\text { (Relationship) Justice }\end{array}$ \\
\hline \hline Key people & Effort exchange; & Legal compliance; & $\begin{array}{l}\text { Psychological contract; } \\
\text { management issues }\end{array}$ \\
& Distribution of earnings/rents; & $\begin{array}{l}\text { Prevention of fraud/corruption; } \\
\text { Bargain and allocation; }\end{array}$ & $\begin{array}{l}\text { Procedural equality; } \\
\text { Interpersonal social }\end{array}$ \\
& Fairness. & Policy consistency. & Relations; \\
& & & Reputation. \\
\hline
\end{tabular}

Comparatively, it has been argued that similar legislation elsewhere does not adequately protect workers who 'blow the whistle' on corporate malpractice. It is possible that Ireland may therefore offer insights about new standards in international best practice regarding whistle-blowing protections, noted in Ireland's move from a country languishing in this arena to one now advancing new regulations on the issue (at least in theory). Legislation in India, UK, US, Australia, South Africa, and New Zealand have all been criticised as flawed (De Maria, 2006; Lewis, 2008; Lewis et al., 2015; Near et al., 1993). For example, De Maria (2006) shows that without any proper benchmarking criteria, it is very challenging to establish what features are necessary to create an equitable and fair whistleblowing system. He further argues there is generally no injunctive relief provided for in whistle-blower legislation, and common law practices make for unreasonable evidentiary demands on those who seek to make a disclosure. Comparative analysis of whistle-blowing protections suggests that many worker rights are symbolic, with limited regulatory impact on corporate power (Devine, 2015). Indeed, there is typically an expansive list of people who are omitted from public disclosure protections (consumers, students, unemployed persons, and retirees). Specific to the UK law (the Protected Interest Disclosure Act 1998, known as 'PIDA'), Lewis (2008) outlines a number of key flaws, including the lack of clear positive rights for workers blowing the whistle; the procedure of investigating a whistle-blower's motive can dissuade a person from making a public disclosure (i.e., the considerable cost and time associated with the resolution of a claim); and the absence of union representatives in the list of prescribed persons, which weakens the opportunity to make a disclosure. The motivation element was removed in June 2013 following numerous cases in which the workers were unsuccessful in their unfair dismissal claim despite making a valid disclosure as the employer established the main reason for the case was to discredit the employer (Inverarity, 2014). Ashton (2015) contends that PIDA has had little impact due to the constant influx of claims. It is possible that the equivalent Irish Act could benefit from such known deficiencies, allowing the implementation of a more effective piece of legislation. For example, the Protected Disclosures Act, 2014, omits a 'good faith' element in whistle-blowing cases, making the motivation of the whistle-blower irrelevant. This requirement was replaced by the necessity for the disclosure to be made 'in the public interest'. This removes the possibility of a case centring 'on the messenger's motives, rather than the message and subsequent handling of it' (Ashton, 2015: 52).

Distributive (resource allocation) justice. The management of people at work is centred on a reward-effort exchange between the buyers (employers) and sellers (workers) of labour power (Edwards, 2003). A consequence of this tension or a perceived imbalance of distributive justice is dissatisfaction or resistance in workplace relations. 
The reward-effort exchange dynamic resonates with whistle-blowing as a potentially distributive justice concept (Table 1). In short, will the new whistle-blowing Act in Ireland engender equality and/or mutual gains collaboration?

Interestingly, Rothschild and Miethe (1999) discuss whistle-blowing as a form of employee resistance when workers face an imbalance in the reward-effort allocation. One suggested reason for a public disclosure as a form of labour resistance is a lack of perceived fairness of resource allocation. The distributive justice dimension suggests that whistle-blowers who potentially face managerial reprisals or perceive the exchange allocation as unfair may then retaliate or resist in ways that expose or seek to undermine employer legitimacy (Near and Miceli, 1996). Miceli and Near (1994) further note the danger or potential misuse of whistle-blower policy by employees alleging a wrongdoing on the part of the company but are either disgruntled workers or dissatisfied low-level performers. As such, opportunistic employees, seeking to retaliate, may engage in whistle-blowing simply to challenge management (Pittroff, 2014).

Of course, dissatisfied workers seeking to make a public disclosure may not do so out of malicious intent. A reported motivator for whistle-blowing has been a deficit of supervisory support for employees (Miceli and Near, 1992), further suggesting that distributive exchange outcomes are possibly connected to worker response actions. Whistle-blowing can also be a response to victimisation by the employer (Grant, 2002). Finally, employees who experience high levels of distress, anger, and fear may be more inclined to react to situations that include some sort of perceived employer wrongdoing (Bjørkelo et al., 2011).

Interactional (relationship) justice. The final dimension in the justice theory framework that connects whistleblowing regulation is that of interactional justice perceptions. Colquitt (2001) notes that interactional justice can be further subdivided into 'informational' and 'interpersonal' justice (Table 1). It is about attendant issues and employee perceptions 'when decision-makers treat people with respect and sensitivity and explain the rationale for decisions thoroughly' (Colquitt, 2001: 386). This is a crucial factor in fostering the behavioural outcomes of trust, mutual reciprocity, and pro-social engagement between managers and workers (Saunders and Thornhill, 2003; Townsend and Dundon, 2015). Interactional justice perceptions and attendant employee behavioural outcomes may be influenced positively and/or negatively, affecting managerial legitimacy, employee truthfulness, respect, and propriety (Bies and Moag, 1986).

The psychological contract is often used to capture many of the interpersonal expectations and obligations of relationship justice between employee and employer (Coyle-Shapiro and Kessler, 2002). It is well established that a positive or violated psychological contract can influence trust and perceived fairness between managers and employees (Flood et al., 2001). In terms of whistle-blowing regulations specifically, the psychological contract can send a key signalling effect to workers and society about the intended fairness of public disclosure legislation (Pittroff, 2014).

Furthermore, when an organisation follows norms and behaviours that comply with societal demands, such as protected public disclosure, it may enhance not only social relationships but also public legitimacy, respect, and propriety or may at least minimise reputational damage in the public sphere (Pittroff, 2014). Importantly, making a public disclosure does not necessarily violate employee-employer relations but may actually be because the workers are committed and loyal to their employer: 'blowing the whistle about one's employer's wrongdoing and being loyal to them serves the same goal, the moral good of the employer' (Varelius, 2009: 265).

Table 1 summarises the overarching justice dimensions that relate to the whistle-blowing regulations. As with many such frameworks, it is inevitably summative; however, it does resonate with key human resource management policy goals of the 2014 Act in Ireland, in seeking to improve greater fairness, transparency, and equity with regard to whistle-blowing protection.

\section{RESEARCH METHODS}

\section{Strategic informants, data collection, and analysis}

Because whistle-blowing has only recently encountered its first legal enactment in the Republic of Ireland, the research is timely. But it can only be exploratory given its early juncture. The core research objective is to explore the potential efficacy and utility of the Public Disclosure Act 2014. The assessment and evaluation of potential efficacy and utility is with regard to the fairness and transparency of the Act to enable and protect workers who may blow the whistle about employer or institutional wrongdoing and malpractice, arising from information and activities in the course of their work (Berg et al., 2005). Perceived fairness and equity with regard to employment and whistle- 
blowing are not straightforward and effects on transparency can be difficult to determine (Ashton, 2015). To this end, the theory of justice and the attendant procedural (legal), distributive (resource allocation), and interactional (relationships) dimensions are offered as potential insights.

A mixed method approach was designed for the research, which involved a three-stage process combining documentary content analysis of public records, followed by key stakeholder interviews. In addition to the 2014 Act itself and numerous media reports on the issues concerned, documents submitted by interested bodies as part of the government's public consultation exercise on the whistle-blowing legislation were examined, along with a small number of interviews with each of the main employment relations actor groups concerned at the time with influencing the drafting of the content of the 2014 Act (e.g., employer bodies, trade unions, and civil servant/ government officials).

The first element involved an examination of the text of the 2014 Act to determine its content and how far regulated discourse is likely to protect workers. This stage also included scrutiny of media reports. The second element involved content analysis of public documents written by interested bodies who advocated a particular position and view on the content of the proposed legislation. These included substantive submissions from Irish Business Employers Confederation (IBEC), Irish Congress of Trade Unions (ICTU), Transparency International Ireland, The Irish Human Rights Commission, and the National Union of Journalists (NUJ), which were all submitted through the public consultation exercise.

The third stage involved interviews with those involved in seeking to influence the content of whistle-blowing regulation with civil servants. This stage involved interviewing the senior representative for each of the main associations regarding whistle-blowing policy from IBEC, ICTU, and the State (senior civil servant from the Taoiseach's office). These three respondents, while numerically small, are strategically significant and unique, representing the most senior key figures involved in drafting this first ever major piece of whistle-blowing legislation. Following Cooper and Schindler (2008), a semi-structured interview format was adopted, allowing for the discovery of any new or emergent issues, as well as an examination of predetermined topics guided by prior theoretical and literature analysis: efficacy, perceptions of justice, fairness, and transparency, as summarised in Table 1.

The choice of a few strategic informants is important. Patton (2002) argues that it is sometimes necessary to select a small number of participants when the topic is new and unexplored, and when there are only a few who have the requisite in-depth knowledge of the area. In our case, the sample size is less important than the quality and uniqueness of the informants and data they offer. In any event, the three strategic informants represent 'all' the people to offer such data at the level of regulatory impact. On that basis, following Saunders and Townsend (2015), the location and strategic positioning of informants offers unique and rare data insights.

Documentary content analysis protocols and interview transcripts were all examined using a thematic schema, which were drawn from theoretical and literature issues discussed in the section on 'Whistle-blowing: justice theory and employment regulation'. The validity and inclusion of themes as evidence were defined as 'a pattern in the information that at minimum describes and organises the possible observations and at maximum interprets aspects of the phenomenon' (Boyatzis, 1998: 161). The content of each document was examined by following this protocol, first to identify the existence and reporting of a theme by evidence of key terms, phrases, linguistic uses, and sentences regarding aspects of whistle-blowing rights, fairness, and justice. The central theme of justice is divided into three dimensions: distributive (economic), procedural (rules/legal), and interactional (treatment within a relationship) justice.

The content analysis of data sources followed a three-stage reliability method (King and Horrocks, 2010). First, descriptive coding was carried out whereby important content was highlighted, e.g., employee protection, rights to speak up. Next, interpretive coding was used to cluster similar phrases, and their meanings were examined and re-examined for reliability and consistency. This technique involves the coding of previous units of data in order to interpret phrase occurrences as indicating normative actor judgments, such as fairness for employees, representative opportunities, regulatory burdens on managers, and so on. Finally, the phraseology of stages 1 and 2 were reviewed for overlapping connections with justice dimensions (e.g., whether procedural or distributive in nature) to make meaningful theoretical contributions from the aggregate data (Saunders et al., 2012: 192).

As with all research, there are limitations, although these have been minimised as far as possible. The three respondents are the key figures involved in drafting the Act and its content for the country as a whole. They are the official agents of the recognised legitimate bodies. Their consent was obtained prior to the interview. All documentary sources and the Act itself are reputable official documents. Overall, there is a degree of internal consistency across different data sources and multiple tools of data analysis (Saunders et al., 2012). 


\section{FINDINGS}

This section reports the findings and highlights a wide variety of motivations for implementing the whistle-blowing regulations in Ireland. Findings are reported concerning the content, motivation, and justice-fairness aspects of whistle-blowing regulations.

\section{Content, champions, and political will}

Content of documentary materials signalled that political values for 'equality in society' were facilitative of the Act. Of particular importance were comparable benchmarks established elsewhere, specifically UK legislation. A senior government civil servant noted that 'significant disasters in the UK in the 80s where in each case an employee had notified their employer of the potential for damage but was ignored' was very much to the fore of Irish government. Documentary data suggested that protecting potential whistle-blowers was a primary aim of the Act: 'ensure that similar and consistent protections are available to as many workers as possible' (Government Reform Unit, 2014: 25). Political champions at the most senior level were also significant. Minister Howlin was noted in documentary evidence and by all respondents as a key driver, following his own personal experience with whistle-blowing when he went before the Supreme Court, due to his refusal to identify who gave him certain information (Howlin, 2013).

The documentary evidence, however, did signal critical concerns about a desire to promote more effective or stronger anti-corruption messages, e.g., from Transparency International Ireland submissions. Reference to other international ideas of best practice, such as reference to the OECD, was also a contributing factor in seeking stronger reinforcement than the Act initially appeared to offer. Concerns included the desire for clear whistle-blower regulations as something that would help attract inward foreign direct investment, by showing Ireland as competing on a comparable world stage as other advanced economies. In general terms, the content of the Act generally accords with such initial claims for more definitive rights, which may not be too surprising given the level of public concern (even outrage) over various headline whistle-blowing cases in Ireland. In short, there was an almost uniform level of political support to enact regulations.

\section{Distributive justice and whistle-blowing}

Mixed opinions emerged regarding the potential content of the Act to ensure fairness and justice. Government officials were clear it would not be a 'panacea' for employment inequalities and concerns are likely to remain about whistle-blowing protection generally. Importantly, multiple data sources signal a number of potential flaws with regard to the elements of distributive justice (job, resource, and remuneration allocation). In particular, perceptions of 'inequality' emerged regarding the definitions and the nature of a potential whistle-blowers' employment status. For example, volunteers are not covered in the Act and the ICTU submission papers signalled these as particular objections, referred to as an 'ambiguous' nature of protection for volunteer workers.

Another issue connected to the exchange effort is the potential 'deterrent effect' of regulatory impact. One rationale for the legislation was cited as deterring reputational damage and financial costs of 'up to 5 years' remuneration' by any firm who punish or victimise a worker who blows the whistle. The intention is for the Act to have the effect of 'protecting reputation, brand and corporate image' by deterring illicit practices by staff and the penalisation of workers. However, several documentary submissions, especially those from both ICTU and IBEC, highlight concerns that caseloads may increase significantly and resources required to support and manage these could be extensive. Furthermore, it remains unclear how line managers or supervisors will manage whistle-blowing issues or deal with workers who may potentially blow the whistle at the workplace level. It is possible that the deterrent effect, as well as the degree to which whistle-blowing policies will be enacted and adhered to, may be more transparent in public sector organisations rather than in private companies.

A further important finding concerns the precarious aspects of work and employment and how these relate to whistle-blowing options, in particular, a limited application of rights for those who are employed in low/minimum wage occupations, those in smaller organisations, workers who lack union representation, and those subject to outsourced or agency-type jobs. Concern was expressed in documentation submission by Transparency International Ireland; the Irish Human Rights Commission confirmed in interview data from ICTU that these occupations may fall outside legal definitions of those protected. The civil servant respondent remarked also that equal treatment may, in practice, 'depend on the nature of the employment relationship and the relative strength of the two parties', and not the content of the Act itself. 
Overall, therefore, the brief analysis of findings point towards ongoing tension, ambiguity, and potential unequal treatment in terms of the application of the new whistle-blowing Act and distributive aspects of the employment contract.

\section{Procedural justice and whistle-blowing}

The government respondent explained an important challenge was to try and 'dampen the expectations of those in favour of the Act while comforting those who were against it'. The ICTU representative noted that a key procedural issue concerned interim relief for whistle-blowers, with a strong ideological aversion to such protections articulated by employers. Procedurally, matters become tricky for a company when a worker makes a protected disclosure anonymously, because under the principle of natural justice, the accused is entitled to know who made the claim. Potentially, the Act undermines or is silent on the principle of natural justice in this regard. Further analysis of documentary submissions from ICTU signalled concerns that the Act was unclear about whether the facility is extended for workers to seek advice from union representatives. Further critique related to the condition that the issue being disclosed must come to the worker's attention 'in the course of employment'. How the course of employment is defined and operationalised in practice is ambiguous, especially for those on outsourced or agencytype contracts.

Of further significance is interview evidence from the IBEC representative, who articulated the view that protections will be a façade, and mostly irrelevant to most businesses on a day-to-day basis. Parallels were drawn between private businesses and organisations such as FIFA, where governance and ethics guidelines of the latter are publically available (on websites etc.), but recent scandals confirm that such self-regulations are a smokescreen. In this regard, the provisions of the Act are unlikely to penetrate what the employer respondent regarded as the 'living culture' of a company, i.e., 'what the people are like, their character'. ICTU, albeit for different reasons, felt limited corporate transparency and organisational openness to be a potential procedural barrier in protecting workers who may consider blowing the whistle about employer wrongdoings:

If the culture is one where no one speaks up because they are afraid to, then simply the fact of the legislation won't change that. (ICTU representative, 2015)

It is evident from the data that the underlying problems relating to procedural fairness relate to organisational cultures, practices, and attitudinal values. In this regard, procedural protections that legislation seeks to advance are unlikely to have substantive impact at these deeper cultural organisational levels.

\section{Interactional justice aspects of whistle-blowing}

The government respondent and related documentary sources noted that the content of the Act supported public interest concerns. In terms of the public good aspect, the Act intends to eliminate corporate (and public service) wrongdoings that are considered harmful to wider society. One goal is that the Act seeks to instil a wider sense of openness within companies. The stepped disclosure mechanism is intended to improve internal communication, while simultaneously reducing corrupt or fraudulent business practices. This provision intends to encourage transparency within companies and support proactive reporting of wrongdoings by workers without fear of any subsequent penalisation. The Act 'provides rules for engagement', which will shape and reconfigure the interactional dynamics of employee-management and union-employer relationships.

However, employers see little value with regard to wider societal concerns, and Fitzgerald (2014b) questions 'whether the pendulum has swung too far' in favour of the whistle-blower. The IBEC respondent repeatedly reflected that whistle-blowing provisions place restrictive burdens on free market commercialisation and managers' presumed right to manage. For IBEC, protecting worker disclosures will amount to 'more grief, more hassle, more publicity, more claims'. From the employer's perspective, the data indicates a distinct perspective in which whistle-blowing protection is perceived as an obstacle to managers' managing. The IBEC respondent felt the Act was a restrictive regulation that will discourage engagement and is unlikely to improve internal relationships. Of particular concern to employers in this regard is that internal resources, and personal energy, will be diverted away from revenuegenerating activities 'in order to deal with potentially groundless claims'. The IBEC respondent further argued that the 'duty to investigate supposed wrongdoings may simply be a waste of resources', adding that 'the Act will become a nightmare charter for "looners" who will want to bring a claim to disrupt business practices by bringing multiple claims even though they know they will lose'. Such scepticism may have the effect of undermining the spirit 
and objectives of the Act, serving to reinforce a managerial agenda of minimal regulation and weakened worker (citizen) protections.

Employer cynicism of the content and purpose of the Act is evident and clear. The employer questions the strength of the Act insofar as limited or light-touch regulation underwrites a free market ideology. The employer association respondent argued that worker protections are not only unnecessary, but in their view, they will also encourage dubious claims by self-interested workers. As such, given such scathing views about the content and purpose of the Act, it is questionable it will 'add to the degree of happiness between workers and employers', as the government official claimed it would.

\section{DISCUSSION}

The data in this article is an initial exploratory examination of the potential of the new whistle-blowing legislation in Ireland to protect workers. The Act and its intended consequences are yet to diffuse into workplaces and wider society, and therefore a full definitive conclusion may have to wait until the terms of the Act are used and tested in the courts. It should also be noted that the data sources are limited, even though they cover the key senior and strategically placed informants for each of the principal actors. Notwithstanding the limitations of any research, the data and its analysis contribute to emerging debates and theory concerning regulatory space and whistle-blowing practice in Ireland, as well as the attendant implications for employment regulation, workplace justice, equity, and transparency.

To begin with, the idea that there is a simplified dichotomy between deregulatory free market forces on the one hand and harder regulatory laws on the other is misleading. The concept of 'regulatory space', including employer power and agency resource mobilisation, signals that employment rights and obligations can be modified in ways beyond the narrow conceptualisation of the State as the single or primary law enforcer. Managerial discourse and its language of 'common knowledge' formation (Culpepper, 2008) show that control and persuasion are powerful sources of influence affecting employment regulation, especially by employer agencies articulating desired (de) regulatory preferences concerning whistle-blowing. In this way, the concept of regulatory space presents as a fluid and dynamic tool that permits an analysis of justice, equity, and fairness as a contestable 're'-regulatory dynamic, the boundaries of which are constantly uneven and power-centric in neoliberal economic regimes (McDonough and Dundon, 2010).

One corollary is that the influence of actors lobbying the content of the 2014 Act are reflective of a minimalist, light-touch regulatory regime, which has the tendency to favour employers and possibly exclude agency or outsourced workers, many of whom are temporary or on undefined contracts and are thus marginalised from labour market institutions. While the Act is a form of statutory (or hard) legislation, its impact may turn out to be much softer in reality even a missed opportunity for the sort of better regulation advocated by the likes of the OECD (2012). In a similar way, O'Sullivan et al. (2015) note that much of the increased employment legislation in Ireland is largely individualistic, favouring employers in actual practice. For example, when legal provisions are individualised, it is difficult for employees to know their rights and to access relevant and accurate information to ensure such regulations are enacted. This issue is compounded with the decline in collective union membership, which can be a valuable conduit for such legal information and enforcement. The result has been the need for other social actors to support workers, such as civil society organisations and citizens' advice agencies, because workers lack collective union representation rights. Arguably, therefore, legal protections such as those in the 2014 Act require employers to do very little and the increased legal right may turn out to be nothing more than a hollow shell, as workers have to trigger progressively individualised protections with declining collective support structures.

At a more practical level, the evidence points to a definitive lack of awareness among some actor constituencies about the tenets of the 2014 Act. It appears there has been limited communication and dissemination about the Act in the public sphere. Of concern is the apparent dissonance between awareness and understanding of regulatory force. While there may be some who are aware of the Act, it is evident from the data that the level of understanding is at best imprecise, at worst insufficient. For example, the government respondent mentioned legal practices offering training on the Act despite not having a comprehensive understanding of it. Blader and Tyler (2003) argue that an understanding of justice assists managers in designing policies that promote the positive outcomes of justice. If there is a deficit of outlets for managers to learn about the Act, they will struggle to first understand it and also to undertake the required obligatory actions. From this observation, one policy suggestion can be ongoing 
awareness communications to engender a more proactive encouragement of whistle-blowing policies to trigger positive change (Ashton, 2015). Hyde (2014) suggests that whistle-blower policies should become a core element of an organisation's corporate risk management strategy, with larger companies designating whistle-blowing officers where possible. Such policies should also highlight the organisation's opposition to such malpractice and clearly communicate the appropriate communication channels should a worker wish to make a disclosure (A\&L Goodbody, 2014). It may also counter the rather biased and unsupportive attitudinal values expressed by the employer association respondent interviewed for this research, who saw worker claimants as self-interested 'looners'.

\section{CONCLUSION}

The research in this article contributes to a growing interest in employment regulation surrounding whistle-blowing. To this end, we contextualised the protective elements of the whistle-blowing Act as offering some new, albeit limited, protections for workers who may blow the whistle. Overall, the Act appears to follow an individual and minimalist regulatory approach favoured by the State and employers. Important in this regard is recognition of a constant or ubiquitous 're'-regulatory employment dynamic. Even free market advocates constantly regulate to deregulate.

Further research of a case study nature in the future, concerning specific whistle-blowing incidents, such as the position of employers if whistle-blowing claims are disproved, would help shed further light on these debates and issues.

\section{References}

A\&L Goodbody. (2014). Protected Disclosures Act 2014 - A New Era for Whistleblowing in Ireland. http://www.algoodbody.com/insightspublications/ protected_disclosures_act_2014_a_new_era_for_ whistleblowing_in_ireland

Ashton, J. (2015). '15 years of whistleblowing protection under the Public Interest Disclosure Act 1998: Are we still shooting the messenger?'. Industrial Law Journal, 44: 1, 29-52.

Berg, S., Gasmi, F. and Tavara, J.I. (2005). Glossary for the body of knowledge on the regulation of utility infrastructure and services. http:// regulationbodyofknowledge.org/wp-content/ uploads/2013/04/glossary_ENGLISH.pdf

Bies, R.J. and Moag, J.F. (1986). 'Interactional justice: Communication criteria of fairness', in R.J. Lewicki, B.H. Sheppard and M.H. Bazerman (eds), Research on Negotiations in Organizations, Greenwich, CT: JAI Press.

Blader, S.L. and Tyler, T.R. (2003). 'What constitutes fairness in work settings? A four-component model of procedural justice'. Human Resource Management Review, 13: 1, 107-126.

Bjørkelo, B., Einarsen, S., Birkeland Nielsen, M. and Berge Matthiesen, S. (2011). 'Silence is golden? Characteristics and experiences of self-reported whistleblowers'. European Journal of Work and Organizational Psychology, 20: 2, 206-238.

Boxall, P. and Purcell, J. (2011). Strategy and Human Resource Management (3rd edn), Hampshire: Palgrave Macmillan.
Boyatzis, R.E. (1998). Transforming Qualitative Information: Thematic Analysis and Code Development, London: SAGE Publications.

Brown, A.J., Lewis, D., Moberly, R. and Vandekerckhove, W. (2014). International Handbook on Whistleblowing Research, Cheltenham: Edward Elgar Publishing.

Carr, I. and Lewis, D. (2010). 'Combating corruption through employment law and whistleblower protection'. Industrial Law Journal, 39: 1, 52-81.

Collings D.G., Gunnigle, P. and Morley, M.J. (2008). 'Between Boston and Berlin: American MNCs and the shifting contours of industrial relations in Ireland'. International Journal of Human Resource Management, 19: 2, 240-261.

Colquitt, J.A. (2001). 'On the dimensionality of organisational justice: Construct validation of measures'. Journal of Applied Psychology, 86: 3, $386-400$.

Cooper, D.R. and Schindler, P.S. (2008). Business Research Methods (10th edn), London: McGrawHill.

Coyle-Shapiro, J. and Kessler, I. (2002). 'Reciprocity through the lens of the psychological contract: Employee and employer perspectives'. European Journal of Work and Organizational Psychology, 11: 1, 69-86.

Culpepper P.D. (2008). 'The politics of common knowledge: Ideas and institutional change in wage bargaining'. International Organization, 62: 1, 1-33.

De Maria, W. (2006). 'Common Law - common 
mistakes? Protecting whistleblowers in Australia, New Zealand, South Africa and the United Kingdom'. International Journal of Public Sector Management, 19: 7, 643-658.

Devine, T. (2015). 'International best practices for whistleblower statutes', in D. Lewis and W. Vandekerckhove (eds), Developments in Whistleblowing Research 2015, London: International Whistleblowing Research Network.

Dundon, T., Dobbins, T., Cullinane, N., Hickland, E. and Donaghey, J. (2014). 'Employer occupation of regulatory space for the employee information and consultation (I\&C) directive in liberal market economies'. Work, Employment \& Society, 28: 1, 21-39.

Edwards P (2003). Industrial Relations (2nd edn), Oxford: Blackwell.

Farndale, E., Hope-Hailey, V. and Kelliher, C. (2011). 'High commitment performance management: The roles of justice and trust'. Personnel Review, 40: 1, 5-23.

Fitzgerald, K (2014a). 'Protected Disclosures Act presents big challenges for employers'. Industrial Relations News, 42, 6-7.

Fitzgerald, K (2014b). 'Devil's in the Detail of New Whistleblower Act', Irish Examiner, 29 December 2014. http://www.irishexaminer.com/business/ features/devils-in-the-detail-of-new-whistleblowerAct-304269.html

Flood, P.C., Turner, T., Ramamoorthy, N. and Pearson, J. (2001). 'Causes and consequences of psychological contracts among knowledge workers in the high technology and financial services industry'. International Journal of Human Resource Management, 12: 7, 1152-1165.

Francis R. (2013). Report of the Mid Staffordshire NHS Foundation Trust Public Inquiry, London: The Stationery Office.

Frenkel, S.J., Li, M., Lloyd, S. and Restubog, D. (2012). 'Management, organizational justice and emotional exhaustion among Chinese migrant workers: Evidence from two manufacturing firms'. British Journal of Industrial Relations, 50: 1, 121-147.

Government Reform Unit (2013). 'Protected Disclosures Bill 2013 Regulatory Impact Analysis'. Dublin: Department of Public Expenditure and Reform. http://per.gov.ie/wp-content/uploads/ProtectedDisclosures-Bill-2013-Regulatory-ImpactAssessment1.pdf

Grant, C. (2002). 'Whistle blowers: Saints of secular culture'. Journal of Business Ethics, 39: 4, 391-399.

Hancher, L. and Moran, M. (1989). 'Organising regulatory space', in L. Hancher and M. Moran (eds),
Capitalism, Culture and Economic Regulation, Oxford: Oxford University Press.

Heffernan, M. and Dundon, T. (2016). 'Cross-level effects of high-performance work systems (HPWS) on employee well-being: The mediating role of organisational justice'. Human Resource Management Journal, 26: 2, 211-231.

Howlin, B. (T.D.) (2013). Minister for Public Expenditure and Reform, 'Protected Disclosures Bill 2013 Second Stage Speech', Speech presented at Public Service Reform and Innovation Conference, 25 September 2013.

Hyde, J. (2014). 'The Protected Disclosures Act 2014: An overview'. Irish Employment Law Journal, 11: 4, 114-119.

Hyman, R. (2008). 'The state in industrial relations', in P. Blyton, N. Bacon, J. Fiorito and E. Heery (eds), The Sage Handbook of Industrial Relations, London: SAGE.

Inverarity, D. (2014). 'Whistleblowing law to mean cultural shift for employers', Industrial Relations News, 28, 24-25.

Kahn-Freund, O. (1977). Labour and the Law. (2nd edn), London: Stevens and Sons.

Kenny, K. (2012). 'Whistleblowing in financial organizations: Towards an identity work perspective'. Discourse and Organization, Vrije University, Amsterdam.

Kenny, K. (2015). 'Constructing selves: Whistleblowing and the role of time', in D. Lewis and W. Vandekerckhove (eds), Developments in Whistleblowing Research 2015, London: International Whistleblowing Research Network.

Kenny, K. (2014). 'Banking compliance and dependence corruption: Towards an attachment perspective'. Law and Financial Markets Review, 8: 2, 165-177.

King, N. and Horrocks, C. (2010). Interviews in Qualitative Research, London: SAGE.

Lewis, D. (2005), 'Providing Rights for Whistleblowers: Would an Anti-Discrimination Model be More Effective?', Industrial Law Journal, 34 (3): 239-252.

Lewis, D. (2008). 'Ten years of public interest disclosure legislation in the UK: Are whistleblowers adequately protected?' Journal of Business Ethics, 82: 2, 497507.

Lewis, D., D'Angelo, A. and Clarke, L. (2015). 'Industrial relations and the management of whistleblowing after the Francis report: What can be learned from the evidence?'. Industrial Relations Journal, 46: 4, 312-327.

MacKenzie, R. and Martinez-Lucio, M. (2014). 'The colonisation of employment regulation and industrial relations? Dynamics and developments 
over five decades of change'. Labour History, 55: 2, 189-207.

McDonough, T. and Dundon, T. (2010). 'Thatcherism delayed? The Irish crisis and the paradox of social partnership'. Industrial Relations Journal, 41: 6, 544-562

Miceli, M.P. and Near, J.P. (1992). Blowing the Whistle: The Organizational and Legal Implications for Companies and Employees, New York, NY: Lexington Books.

Miceli, M.P. and Near, J.P. (1994). 'Relationships among value congruence, perceived victimization, and retaliation against whistle-blowers', Journal of Management, 20: 4, 773-794.

Near, J.P. and Miceli, M. P. (1985). 'Organizational dissidence: The case of whistle-blowing'. Journal of Business Ethics, 4: 1, 1-16.

Near, J.P. and Miceli, M. P. (1996). 'Whistle-blowing: Myth and reality'. Journal of Management, 22: 3, 507-526.

Near, J.P., Morehead Dworkin, T. and Miceli, M. P. (1993). 'Explaining the whistle-blowing process: Suggestions from power theory and justice theory'. Organization Science, 4: 3, 393-411.

OECD. (2012). Better regulation in Europe - the EU 15 project, http://www.oecd.org/gov/regulatory-policy/ betterregulationineurope-theeu15project.htm

O'Sullivan, M., Turner, T., Kennedy, M. and Wallace, J. (2015). 'Is individual employment law displacing the role of trade unions?' Industrial Law Journal, 44: 2, 222-245.

Patton, M.Q. (2002). Qualitative Research and Evaluation Methods (3rd edn), Thousand Oaks,

\section{CA: SAGE.}

Pittroff, E. (2014). 'Whistle-blowing systems and legitimacy theory: A study of the motivation to implement whistle-blowing systems in german organisations'. Journal of Business Ethics, 124: 3, 399-412.

Regh, M.T., Miceli, M.P., Near, J.P. and Van Scotter, J.R. (2008). 'Antecedents and outcomes of retaliation against whistleblowers: Gender differences and power relations'. Organization Science, 19: 2, 221240.

Rothschild, J. and Miethe, T. D. (1999). 'Whistle-blower disclosures and management retaliation: The battle to control information about organization corruption'. Work and Occupations, 26: 1, 107-128.

Saunders, M., Lewis, P. and Thornhill, A. (2012). Research Methods for Business Students (6th edn), Harlow: Pearson Education Limited.

Saunders, M. and Thornhill, A. (2003).'Organisational justice, trust and the management of change'. Personnel Review, 32: 3, 360-375.

Saunders, M. and Townsend, K. (2015). 'Reporting and justifying the number of interview participants in organisation and workplace research'. Paper presented at the British Academy of Management, University of Plymouth, 8-10 September.

Townsend, K. and Dundon, T. (2015). 'Understanding the role of line managers in employment relations in the modern organisation'. Employee Relations, 37: 4, 1-10.

Varelius, J. (2009). 'Is whistle-blowing compatible with employee loyalty?' Journal of Business Ethics, 85: 2, 263-275. 